\title{
The Future Isn't What It Used To Be $\dagger$
}

\author{
Edgar S. Dunn, Jr.
}

In order to make and illustrate my point we need to set the stage. I want you to oblige me by visualizing the region-urban system in a certain way. First, I want you to see the urban system as a connective, transaction network linking all activity sites. See this as a pervasive characteristic of the urban system at every scale: there are networks that link factory work stations, networks that link the primary transactors (households, enterprises and governmental agencies) at the scale of town or city, networks that link primary transactors at the scale of the urban region, networks that link transactions at the level of geographical regions and at the national scale. They are all, of course, different scalar abstractions of one seamless network. Corresponding to this image is the concept that, if at any scale there exists an identifiable entity (city or region), it is primarily because it exhibits a degree of network closure that internalizes a larger set of its transactions than it mediates cross-boundary.

Second, I want you to see the urban network structure that exists at any time as the result of an historical process. Its explanatory roots are to be found in the dynamics of that process.

Third, I want you to see that process as being an inherently evolutionary one such that in each historical situation (1) the primary transactors encounter a set of problems peculiar to their situation; (2) they invent and innovate a series of technological solutions (technology broadly conceived); (3) that in the process they modify the linkages that define the urban system network and the activity-site pegs upon which it is hung; and (4) that the new solutions and network structures then make manifest a new set of problems driving the system to the next iterative round of adaptations.

It is useful to characterize historical epochs in terms of their dominant problem concerns and the technological characteristics of the solutions they evoke. When we do this we can see that the urban transaction network takes on a structure reflecting the underlying "techno-logic" of the time (forgive the coinage). The effect of technological change upon urban structures is mediated in two ways. First, changing technology acts to modify the network structure of the transportation and communication channels carrying all inter-entity transactions. Further, by changing the design of the system's production processes, changing technology redefines the input-output linkages that pattern the transactions linking them.

†An address delivered at the April 15, 1981 meeting of the Southern Regional Science Association, Rosslyn, Virginia, upon his election as a Fellow of the Association. 
The two kinds of effects act together to determine urban transaction structures in every epoch.

Let me dip into the history of the U.S. urban system to demonstrate how each historical epoch has been marked by a different set of compelling problems and responding technological solutions; and how these, in turn, placed a different stamp upon urban transaction networks and settlement patterns. Because of time limits I can only be suggestive, and I will restrict our attention to the network consequences of transportation and communication developments.

As the nation made the transition from an agrarian to an industrial economy during the 19th century, the major problem was how to gain effective access to the vast continental interior. The first round of technical adaptations married the steam engine with the boat and "iron horse." This turned the rivers into two-way streets for the first time and permitted a shallow penetration of the interior adjacent to waterway nodes. This was the first time the nation achieved anything like a national transport system. It permitted a set of interior cities to come to prominence for the first time. It permitted the first genuine urban hierarchy to emerge.

But this technology was insufficient for linking the Far West into the national system. Low-pressure steam engines and brittle iron rails were not adequate to provide effective land transport over such distances. The technological adaptations created the modern railroad and the steel industry and shifted the nation's resource base from wood to coal. These adaptations also reorganized the nation's urban system. Riverine towns and cities declined while others emerged. The steel industry built the base of a westward-extending manufacturing belt. But most importantly, the new industrial economy became an urban economy oriented to the nodes of a highly linear transport system.

This circumstance created still another set of dominant problems. The new, densely-packed cities soon had to spread to breathe, but the access technologies that had absorbed the nation's developmental energies for so long were ill-suited to relieving the now-pressing, localized intra-regional access problems. The telephone, streetcar and urban public utilities were the technological solutions that relieved the pressures in the late 19th century. But the cinch binding the city was only breeched by this technology along selected radial spokes.

So the access problem commanding attention shifted once more. Until some mode of transport came along that provided greater local time-androute flexibility, the city continued to struggle to house the activities and populations of the industrial economy. The technological adaptation was the petroleum-based internal combustion engine. It was the motor vehicle that finally ungirded the city and created the spreading interstitial suburbs.

By the end of World War II the most obtrusive access problems shifted again-back to the scale of the national system. The increasingly complex industrial transaction network had been forced into a set of national transport channels still largely linear and arterial in form. Something like the articulation of connective options that had been achieved at the local 
level was needed at the national level. Paramount among the developmental responses was the long-distance trailor truck; the national highway system; a nationwide, motor vehicle service infrastructure; the new direct-dial, long-lines telephone system; and modern air transport.

The consequences of these changes were extraordinary. They yielded a phenomenal increase in the density of transportation and communication networks. This reflected (a) an increase in the total length of the transfer channels serving a given unit of surface, (b) an increase in the number of route segments, (c) an increase in route flexibility, especially through the rapid increase in cross-arterial channels and (d) an increase in the surface extension or enlargement of urbanized fields served by highly connected networks. This increase in connective articulation took place at every network scale: at the scale of the town or city, at the scale of the transaction fields forming an established urban region, at the scale of the broad geographical region or nation system.

These channel alterations changed the urban transaction network in ways without historical precedent. An idea of the impact can be suggested by roughly dimensionalizing the enlargement of the geographical fields within which significant network alterations took place. At the microscale the amount of rural land converted to the uses of town and city amounted to 27,000 square miles. At the middle scale the primary commuting field of the nation's core cities was extended by 270,000 square miles-more than enough to contain all of Japan and the United Kingdom put together. At the macroscale we learn of the dramatic changes from the work of our program director, Dick Olsen. Using a truncated gravity model he demonstrated that, in 1950, the portion of the United States accessible to a population of 25 million people within an eight hour road trip was restricted to two small enclaves; one along the Middle Atlantic Coast and the other covering the Chicago-Cleveland-Detroit area of the Midwest. By 1970 that field had expanded to cover the entire eastern half of the United States (east of Dallas, Kansas City, and Des Moines). The same data can be used to demonstrate that the broad regional changes in population access by highway tripled in those twenty years. Furthermore this was the period when telephone and air travel networks became highly articulated. There is little doubt that, if it could be calculated at all scales of social transaction, the connectivity or accessibility of the total urban system must have changed by at least an order of magnitude. There is equally little doubt that this was unprecedented in historical experience up to this time, and remains unmatched elsewhere in the world.

Beyond this rough dimensionalization, important changes in structure are also taking place.

(1) The urban system is experiencing a reduction in the levels of hierarchy required to organize system transactions. The classical "switchboard" function of the American city and town is more evenly distributed. This attends the fact that direct point-to-point transfers are more often feasible. There is an associated tendency for lower-order nodes to mediate transfers. 
(2) As a consequence, urban transaction systems are becoming more open. The percentage of transactions internalized by any bounded transaction field tend to decline relative to cross-boundary transactions originating or terminating in that field.

(3) The transaction network is becoming more of a continuous-flow network. Not only do pipelines and power lines form a much larger part of the whole transfer system, the traditional transfer modes have begun to take on continuous-flow characteristics. The enlarged transfer options, especially the increasing span of communication and control, substantially decrease the amount of time-and-space buffering required of conventional commodity inventories. The entire urbanized network is moving closer to operating on a realtime basis over much wider fields of interaction.

(4) These changes in transaction network structure are facilitating changes in the orientation of enterprises and households. These, in turn, feed back upon and reinforce the changes in network structure. For example, the extended fields of access and spans of effective organizational control permit enterprises to split their organization along functional lines. Thus, each subsystem, like production, sales, and management, can find its most advantageous locus among a vastly expanded set of nodal options in the urban field.

All of this reorders urbanized activities and settlement patterns at every scale. The detail is fascinating, had we the time to look at the record. But I hope that this narrative has been sufficient to illustrate the way in which problem-solving adaptations progressively redefine the techno-logic of the urban system's transaction networks, and, hence, the distribution in space of activities and populations. I hope that it also serves to illustrate why the future is never what it used to be. If we want to look past this moment in history, we can be sure that the next generation, like all of those that preceded $i$, will experience a reorientation of its urbanized transactions networks in response to emerging, problem-solving developments.

If you will now turn to face the future with me for a few moments, I will discard sensible caution, gather my courage and make an assertion: our society is already engaged in negotiating a major phase-shift between the industrial society we have known for 150 years and an emerging information society. It is doing so in pursuit of a different agenda of problems and it is responding with a technology that promises to reorder urban transaction systems once more.

The interesting thing is that this process traces its roots back into the 19 th century and has already come a long way. Yet the process has gone largely unnoticed. Why? Largely because it has been a subterranean process. Our data classifications hide it. There is no such thing, for example, as an information industry. It is an activity change that has invaded and transformed every industrial sector and occupation. It is also partly because the conceptual imagery of the industrial age inclines us to identify "real" production in terms of physical products. It has also come on very fast. After the onset of the industrial era, it took over 100 years before manufacturing employment passed agricultural employment. It took only 
50 additional years for information processing employment to surpass all other categories of employment, and this by imperfect estimates that likely underestimate information processing employment. This took place barely 20 years ago and the fact still has not penetrated social consciousness.

What led to this spectacular change? That is a story that could easily engage us for the rest of the afternoon. Let us simply observe that the mechanization processes of the industrial era sowed the seeds. They served to externalize a large portion of the how-to-do-it knowledge and skills of the physical production worker. These information processes became hardened into the design of the machine. The amount of human information processing that remained to engage the worker at each work station was dramatically reduced. The amount of genuine physical work left was even more dramatically reduced. The worker became primarily a machine operator and product assembler, both largely simplified cybernetic or information processing roles.

Paradoxically, this had the effect of vastly increasing social information processing requirements. The segmentation of process sequences created a whole new set of problems because these processes required linking in time and space. Enterprise production systems emerged that linked work stations. Urban transaction systems arose that linked enterprise production systems and households through transportation and communication systems. But for coherent patterns to emerge, all of these flows required intelligent coordination. The information processing requirements were displaced upwards. The foreman ceased to be a master craftsman and became a business school graduate. Urbanized transfers became dependent upon a host of transaction specialists increasingly more absorbed with the records of transactions than with the physical transfers. The new industrial technologies and their linkage requirements placed great strains upon information processing technologies by shortening the time span and extending the space span subject to real time control. But information processing requirements were not boosted by the need to maintain coherent production and distribution systems alone. They were expanded by the creative requirements of designing, producing and installing the industrial technology that enlarged society's capacity for physical production. They were further expanded by the success of industrial technology in expanding human wants. Increasingly, people were freed to look beyond physical satisfactions to the psycho-social rewards of exercising their human creative potential. But the sciences, arts, crafts, spectator sports and religions occupying them in this quest are all predominantly information processing exercises.

During my generation the system arrived at the point where further productivity gains, and the satisfaction of emerging human aspirations, were primarily constrained by inadequate information-processing technologies. We are now poised at the moment in history when our problemsolving potential has come to focus upon these processes.

In this connection I would like to call your attention to a characteristic of the development of the last 30 years that has largely escaped attention. The 
phenomenal increase in the connective articulation of the urban network already observed is an early manifestation of this emerging change. It could never have taken the form that it did without recent developments in telephone technology. I would also invite you to notice that the airplane, while classed as physical transport, is basically a communication device. It was created for the purpose of transporting information in people packages. So, too, was the automobile. You can see that the logic of this articulating urban network is already being bent away from the logic of industrial processes.

I would suggest to you that the emerging information processing technology promises to further change the shape of the urban transaction network. This seems inevitable for several reasons: (1) the techno-logic of communication channels is different from that of transportation nets; (2) emerging developments promise to exaggerate the differences; (3) the relative increase in the share of all transactions taking the form of information transfers promises to give this difference increasing importance in determining the structure of the emerging urban transaction network.

Consider, first, the difference. Modern communications technology eats up time and distance unlike any physical transport technology. Already, for regular long-lines service, area-code 800 watts-line calls, and long distance, costs have become so negligible that, for most communications, sending-and-receiving-site choices are rarely influenced by transfer costs. This sort of thing stands traditional Weberian location theory on its head.

Consider, next, the growing significance of the difference between communication and transport technologies. There are several aspects of increasing significance for urban system structure.

First, the signal capacity of communication channels is currently increasing geometrically and will continue to do so for quite some time. These work-horse capabilities will be rapidly carried into every corner of the nation. Coaxial cables, fiber optics and satellite communications are all technologies that will be playing a role, and their potential is barely scratched. All of these technologies open up efficient, low-cost paths for visual as well as spoken communications, and for large volume alphanumeric data transmissions, all far beyond the capacity of dedicated telephone lines. The capacity of these channels, and their flexibility in use, is vastly expanded when coupled with computers. Emerging computer technologies will provide an unlimited range of new applications including two-way, or interactive, communications over the full range of conceivable channel requirements. What would be considered remote locations in terms of the logic of physical transport will become quite accessible to information processing activities.

Second, in the domain of information processing the new technology will all but wipe out the meaning of a technological distinction as hoary as history. The technological processes engaged in physical production have generally been different in character from those that have supported the transfer of goods in space. Historically, this has given a critical importance to the interface between production and transport. The network structure 
of urban systems has been dictated by this technological distinction throughout organized social history.

Once information processing assumed electronic form, the theoretical potential existed for reducing this kind of technological determinism. The reason is of critical importance. In information processing, both communication and basic alpha-numeric techniques involve identical root processes - this in marked contrast to the corresponding production and transport processes in the physical realm. Both information transfers and transformations involve the movement of electronic signals in paths and the switching of these signals from one channel to another. The main technological difference between communicating, computing or storing information is the sequence in which the switching operations are performed. We are dealing with a totally integrated technology where the different operational functions are no longer distinguishable by their technological form.

The network implications are profound. In the realm of information processing there is no longer any compelling technological reason for the interface between transformation processes and transfer processes to have the same operational significance. When you combine this with the fact that the relative space and time costs of communications will be declining rapidly, the location of information processing activities will increasingly experience a degree of locational freedom never enjoyed (and indeed never to be enjoyed) by physical processes.

Such changes cannot help but become reflected in the structure of urban transactions. They open the way for information processing subsystems to become widely separated in space without loss of efficiency and with relatively little space-cost penalty. This is becoming true at every scale and opens the way for a widespread substitution of communications for transportation-particularly where it has been traditional to transport information in people packages and in books and printed documents. It is becoming possible to subdivide both enterprise and household functions and distribute them around the entire nation (or, indeed, around the world) and for the enterprise to still operate as a coherent entity when it matters.

In the long-run it may also turn out to be equally important that this new information processing technology will feed back upon, and radically alter, the nature of physical production processes. By marrying the new technology to industrial technology we are well on the way to producing and employing "smart robots" that can replace the machine tender and product-assembler at the production work station. Some automation experts are saying that this hybrid technology may potentially replace twothirds to three-fourths of today's factory work force. We cannot yet begin to anticipate the multitude of ways such a development will change the input-output linkages that help determine the structure of urban transactions. Consider just two illustrative possibilities. One consequence might well be a shorter work week. But a shorter work week would further weaken the increasingly tenuous linkages between the household and traditional production work site. Second, the old industrial technology 
dictated long, fixed production runs in order to achieve economies of scale. The new technology opens up the possibility of made-to-order manufacturing. This could substantially change the matrix of linkages connecting production to final demand through intermediate trade sectors.

We could go on in this fashion, but you get the point. A phase-shift of major proportions is taking place in the technological base of the urban economy. It promises to generate substantial changes in the structural logic of urban transaction networks.

All of this leads to another topic. The future is not going to be what it used to be for regional science as well. At this point I would like to be able to start a new address and cannot. Let me just leave you with this thought. If regional science is to concern itself with the kind of agenda I have discussed with you, we will have to begin to find ways to deal with research problems that require data and methods we are not used to employing. 